\title{
NOVEL SETTING AND DESIGN OF RELAY FOR PROTECTION OF 3- PHASE INDUCTION MOTOR USING PSCAD
}

\author{
Pathik N. Shah ${ }^{1}$, Smith N. Patel ${ }^{2}$, Jay A. Patel $^{3}$, Umang S. Wani ${ }^{4}$ \\ ${ }^{I}$ Student, B.Tech Electrical Engineering, C. G. Patel Institute of Technology, Gujarat, India \\ ${ }^{2}$ Student, B.Tech Electrical Engineering, C. G. Patel Institute of Technology, Gujarat, India \\ ${ }^{3}$ Assistant Professor, Department of Electrical Engineering, C. G. Patel Institute of Technology, Gujarat, India \\ ${ }^{4}$ Assistant Professor, Department of Electrical Engineering, C. G. Patel Institute of Technology, Gujarat, India
}

\begin{abstract}
This paper is designed to protect an Induction Motor from different types of abnormalities. Providing protection for motors is very important in industries, power plants etc. such that production is not hampered owing to failure of any motor. Purpose of motor protection is to limit the effect of disturbances and stress factors to a safe level. If a motor failure takes place, the protection is needed to disconnect the motor from the supply network in due time. Here we have described different abnormal conditions in three phase induction motors and designed a protective scheme to protect it from different abnormalities. We have also described the method which shows how to set electromagnetic relay for large motor and also described the same method in case of numerical relay. Here we have shown one of the faulty condition with the help of PSCAD (student version).
\end{abstract}

Keywords: Induction motor, Relay, PSCAD student version.

\section{INTRODUCTION}

Electric motors are exposed to many kinds of disturbances and stresses. Part of the disturbances is due to imposed external conditions such as over-voltage and undervoltage, over-frequency and under-frequency, unbalanced system voltages and supply interruptions. Other possible causes of external disturbances are dirt in the motor, cooling system and bearing failures or increase of ambient temperature and humidity. Stress factors due to abnormal use of the motor drive are frequent successive startups, stall and overload situations including mechanical stress. The above stress and disturbances deteriorate the winding insulation of the motor mechanically and may eventually lead to an insulation failure.

\subsection{Introduction to Motors}

There are many different types and sizes of motors used in practice. This paper deals with protection arrangement for large 3-phase induction motors. The motor rated upto 415 volts can be protected by starters of various kinds having inbuilt thermal overload relays and no-volt release facility, and very often protection for short circuits can be provided by switch-fuse units. Large and medium range 3-phase induction motors are used for running power station auxiliaries and in large industries for various purposes. These motors are controlled by circuit breakers and associated protective relay. Such motors need comprehensive protective arrangement to achieve the desired degree of security and dependability.

\subsection{Introduction to Relays}

A relay is an electrically operated switch. Relays are used wherever it is necessary to protect equipment which plays a vital role in industries. There are different types of relays according to their principles and construction. Majorly they can be classified as electromagnetic relay, static relays and numerical relay. Electromagnetic relays contain the moving parts due to which its construction becomes difficult so static relays are used which does not contain any moving parts, they are usually made up of active semiconductor devices such as diodes, transistor, IC's etc. which process the electrical inputs to get desired relay or the numerical relay has many advantages compared to other two types of relays. From storing of historical data to group settings, it also gives us the facility such as flexibility, compactness, self-checking facility, simplicity of interfacing with CT and PT, time synchronization with GPS system and many more facilities.

\section{TYPES OF ABNORMALITIES IN MOTORS}

There are different types of abnormalities because of which the motor fails to start or behaves abnormally. Some of the abnormalities can be explained as below.

\subsection{Overloading}

Motor overload condition is mainly a result from abnormal use of motor, harmonics or unbalanced supply voltages. The load on the motor is mechanical load. When mechanical load on the motor is gradually increased, the speed of the motor gradually decreased and slip is increased. With increase in the slip the current increases. The heat generated goes on increasing the temperature of the winding and with 
increase in the temperature, the rate of heat dissipation also increases. In this manner when the load is increased beyond the rated load the current will increase to subsequently very high level. The conductors of stator and rotor are not affected in due to this increase in the temperature but the insulation around these conductors is certainly affected. The insulation can get detoriated due to temperature rise and can eventually fail. The curve plotted below shows the maximum allowable time v/s multiples of rated current of induction motor. If the motor is overloaded in cold condition, the time ordinate will be higher than when motor is overloaded to the same level from the hot condition. So accordingly, we get two almost parallel curves namely 'Cold curve' and 'Hot curve'.

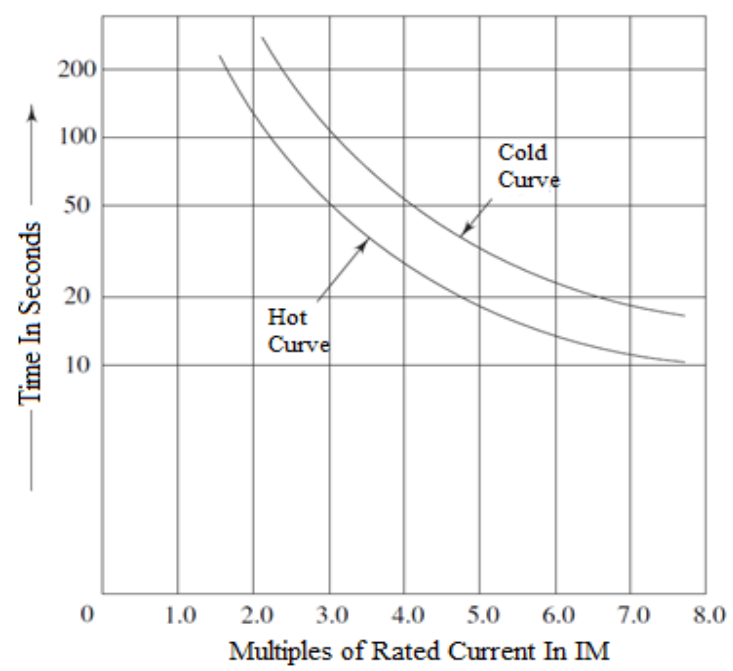

Fig -1: Thermal withstand characteristics of induction motor

\subsection{Single Phasing}

Single phasing can occur as a result of fuse blowing or one phase conductor develops an open circuit fault or in case one pole of a circuit breaker not making contact while an induction motor is running. If the motor is loaded more than it's rated full load, the torque produced by the remaining two positive rotating fields continues to rotate the motor and develops the torque demanded by the load. Due to this voltage may be nearly equal to phase voltage that was lost but it will draw excessive current, due to this, motor will heat up quickly. Due to single phasing, an unbalance current also takes place. The negative sequence component of this unbalance current causes the rotor to overheat. The motor becomes noisy and starts vibrating due to uneven torque produced in the motor. The windings may melt due to overheating and can give a fatal shock to the personnel.

\subsection{Unbalanced Current}

Unbalanced phase currents are the source of negative sequence current in the motor. Unbalanced voltage causes negative phase sequence voltage to be developed and the negative sequence currents generated will be approximately 6 times the negative sequence voltage. Form the utility perspective, unbalance voltages may be caused by frequently increase or decrease in the load or possibly by fuses being blown on distribution capacitors. For the costumer, current unbalance can cause adverse effects on motor including the damaging of motors.

\subsection{Stalling}

When the heavy load is thrown on the motor abruptly the will stall. If there is heavy load on the motor at the time of starting, the motor cannot start and the rotor gets blocked. In such a condition the motor is said to be stalling. The rotor of induction motor may be locked because of gear drive jamming or bearing failure. Under the condition of stalling or locked rotor, the speed of the rotor will be very small or most often zero. In this condition, the motor will draw a very high current of order of $15-20$ times the rated current.

\subsection{Undervoltage}

If the voltage drops when the motor is running at the full rated load, the current taken by the motor increases. This is because the power to be delivered remains constant and the voltage is reduced from the normal rated voltage. The effect of an increased motor current can cause damage to the insulation of the motor windings.

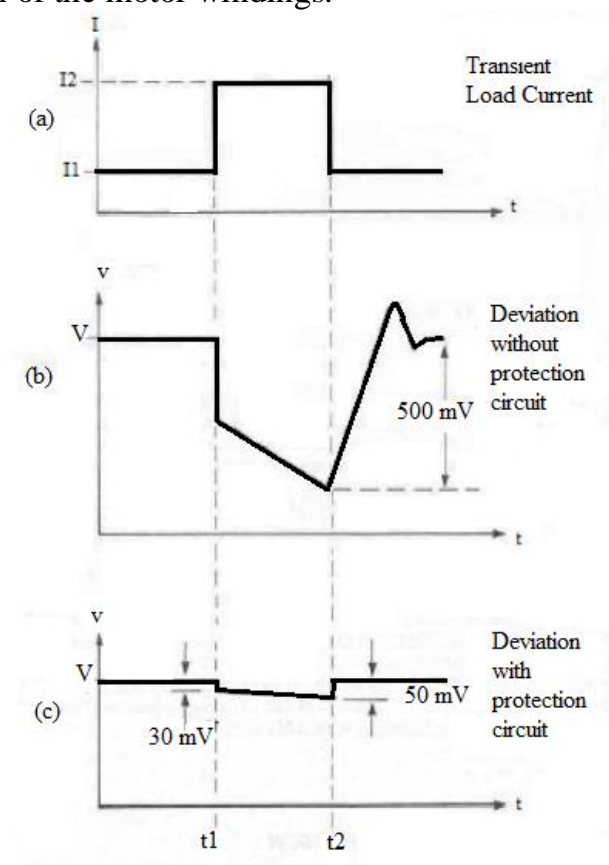

Fig -2: Voltage dip

\subsection{Reversed Phase Sequence}

If the phase sequence in the supply circuit of an induction motor is reversed only the negative sequence currents are taken by the motor and the motor will run in the opposite direction when started. The loads like fan, pump etc cannot be run in the other direction than the one which they are meant to run. Hence, reverse rotation will damage the load. 


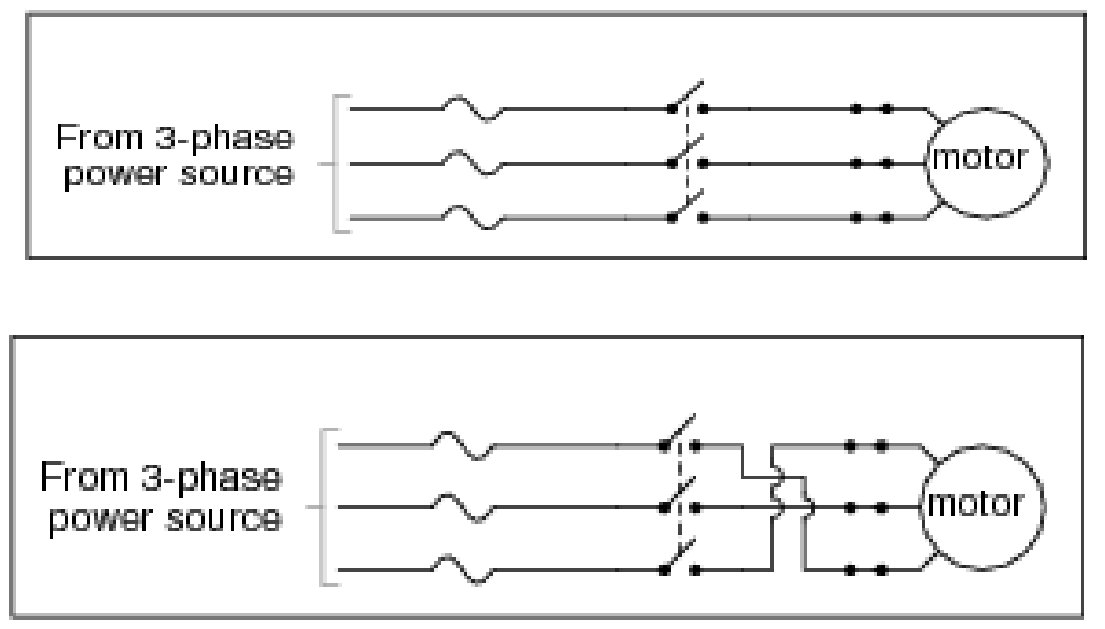

Fig -3: Phase Sequence reversal

\section{PROTECTION FROM ABNORMALITIES}

As shown above, the motor suffers from many abnormal conditions in the field due to which the capital cost of replacing the motor may be costly. It is better to prevent the fault but in case if the system fails to prevent the fault, a protective scheme must be approached.

\subsection{Thermal Overload Protection}

The majority of winding failures are either indirectly or directly caused by overloading operation on unbalanced supply voltage, or single phasing, which all leads through excessive heating to the deterioration of the winding insulation until an electrical fault occurs. The generally accepted rule is that insulation life is halved for each $10^{\circ} \mathrm{C}$ rise in temperature above the rated value, modified by the length of time spent at the higher temperature. As an electrical machine has a relatively large heat storage capacity, it follows that infrequent overloads of short duration may not adversely affect the machine.

However, sustained overloads of only a few percent may result in premature ageing an insulation failure. Furthermore, the thermal withstand capacity of the motor is affected by heating in the winding prior to a fault. It is therefore important that the relay characteristics takes account of the extremes of zero and full load pre-fault current known respectively as the 'Cold' and 'Hot' conditions. Below figure shows that the thermal relay shall not to be operated when the motor is started. If relay operates during starting of motor, the hot characteristic gets overlapped with the motor characteristic which is shown below. This condition should be avoided.

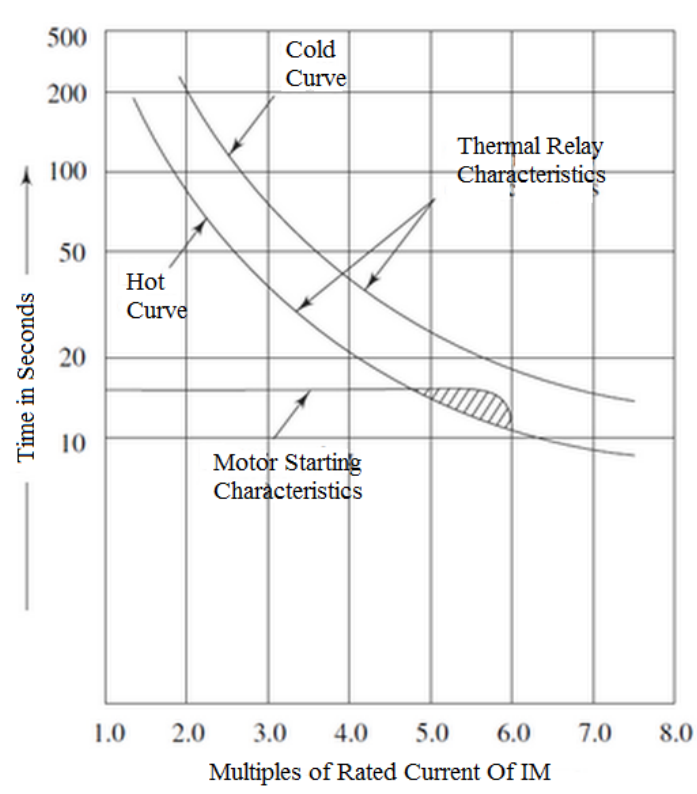

Fig -4: Incorrect selection of thermal relay

\subsection{Short Circuit Protection}

Motor short-circuit protection is often provided to avoid major stator winding faults and terminal flashovers. As the stator windings are completely enclosed in grounded metal, the fault would very quickly involved earth, which would then operate the instanteous earth fault protection. A single definite time overcurrent relay element is all that is required for protection. The time delay is required to prevent spurious operation due to CT spill currents. The normal definite time overcurrent protection would not be sufficiently sensitive, and sensitive earth fault protection may not be provided. An instanteous overcurrent relay can be used for protecting the motor against such conditions with pick-up setting equal to a value of starting current at $75 \%$ of the rated voltage can be selected.

\subsection{Negative Phase Sequence Protection}

Negative phase sequence is generated from any unbalanced voltage condition, such as unbalanced loading, loss of a 
single phase, or single-phase faults. The latter will normally be detected by earth fault protection; however, a fault location in a motor winding may not result in the earth fault protection operating unless it is of the sensitive variety.

There are two strategies for this purpose, one uses definite time overcurrent relay. Time delay is kept of 6 to 10 cycles, high current drawn during starting of the motor i.e. 15 to 20 times the rated current can bypassed. Thus, for some time, current seen by relay is zero. The pick-up ratio of definite time overcurrent relay is normally set on $50 \%$ of starting current of an induction motor.

Another purpose is better practice as the tripping time is inversely proportional to the square of negative phase sequence current of the stator. This setting is based on $\mathrm{Z}_{2} / \mathrm{Z}_{1}$ ratio and is normally set at $20-80 \%$ of the relay setting.

\subsection{Protection against Stalling}

In certain cases of heavy overloading, the motor may not fully stop running but speed variations may be found around a lower steady-state speed. If these variations are at a safer limit with respect to electrical and mechanical stresses on the motor insulation and rotor parts respectively, and the motor has not lost synchronism, certain time is needed by the motor to gain a steady and stable state. This time is called safe stalling time. In such cases, immediate tripping is not required but the scheme should be made such that it restrains for some time and a situation still persists, tripping occurs.

Motor stalling can be recognized by the motor current exceeding the start current threshold after a successful start - i.e. a motor start has been detected and the motor current has dropped below the start current threshold within the motor safe stall time. A subsequent rise in the motor current above the motor starting current threshold is then indicative of a stall condition, and tripping will occur if this condition persists for greater than the setting of a stall timer. A definite time overcurrent relay element provides protection.

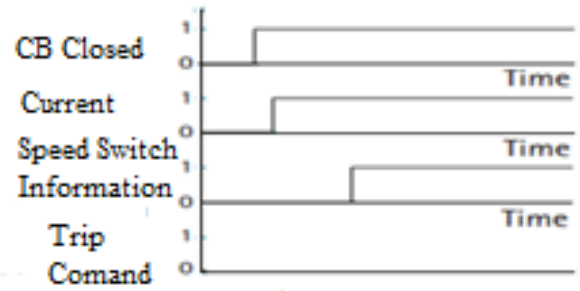

(a) Successful Start

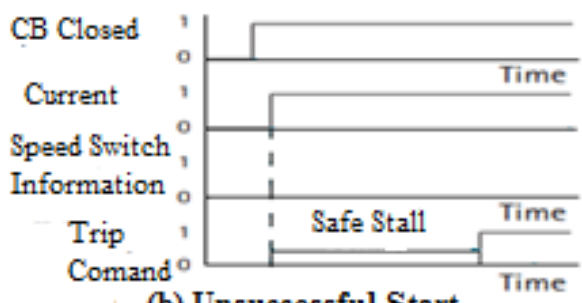

(b) Unsuccessful Start

Fig -5: Safe stalling time

\subsection{Earth Fault Protection}

One of the most common faults to occur on a motor is a stator winding fault. Whatever the initial form of the fault or the cause, presence of surrounding metallic frame and casing will ensure that it rapidly develops into a fault involving earth. Therefore, providing earth fault protection is very important.

Earth fault protection is usually provided by a simple instantaneous overcurrent relay and is normally set at $20 \%$ of the full load current of the motor. In this scheme, operation of the relay due to saturation of the CT during initial high starting current should be avoided. This can be achieved by increasing the voltage setting of the relay by inserting a stabilizing resistor in series with it.

\subsection{Under Voltage Protection}

When a specific undervoltage trip is required in the industry or at power stations, a definite time overvoltage element is used. If two elements are provided, alarm and trip settings can be used. The voltage and time delay settings will be system and motor dependent. They must allow for all voltage dips likely to occur on the system during transient faults, starting of motor, etc. to avoid spurious trips. As motor starting can result in a voltage depression to $80 \%$ of nominal, the voltage setting is likely to be below this value.

\section{SETTING FOR ELECTROMAGNETIC \\ RELAY}

\section{Rating of an Induction Motor}

Output Power $(\mathrm{Pa})=1200 \mathrm{~W}$

Efficiency $=90 \%$

Power factor $=0.8$

Rated voltage $=6.6 \mathrm{kV}$

Starting time at $100 \%$ voltage $=10$ seconds

Starting time at $80 \%$ voltage $=15$ seconds

\section{Rating of the Relay}

Staring Current $=6$ times rated current

Safe stalling time $=20$ seconds

CT ratio $=200 / 1 \mathrm{~A}$

Permissible continuous overload withstand $=110 \%$ of rated current

Negative sequence impedance $Z_{2}=20 \%$

Positive sequence impedance $\mathrm{Z}_{1}=80 \%$

\section{Setting of the Relay}

\begin{tabular}{|l|l|}
\hline Thermal Overload Relay & $70-130 \%$ \\
\hline Instanteous Overcurrent Relay & $400-2000 \%$ \\
\hline $\begin{array}{l}\text { Negative Phase Sequence } \\
\text { current relay }\end{array}$ & $10-40 \%$ \\
\hline Under voltage relay & $70-110 \%$ \\
\hline $\begin{array}{l}\text { Definite time overcurrent } \\
\text { (Stalling) Relay }\end{array}$ & $150-600 \%$ \\
\hline
\end{tabular}




$$
\begin{gathered}
\text { Efficiency }=\frac{\text { Output }}{\text { Input }} \\
\text { Input }=\underset{\text { Efficiency }}{\text { Output }}=\frac{1200}{0.9}=1333.33 \mathrm{~kW}
\end{gathered}
$$

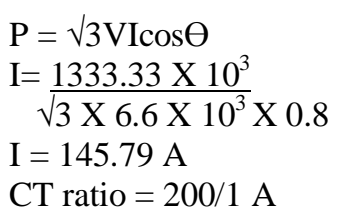

If $200 \mathrm{~A}$ passes through the $\mathrm{CT}$ primary and $1 \mathrm{~A}$ from $\mathrm{CT}$ secondary, then for $145.79 \mathrm{~A}$ then $0.7289 \mathrm{~A}$ passes through the CT secondary.

\section{For Thermal Overload Relay}

This relay picks up at the $105 \%$ and trips at $110 \%$ of relay setting.

Therefore,

$\underline{0.7289 \times 1.1}=0.763$

1.05

$0.763 \times 100 \%=76.3 \%$

The thermal overload relay has the range of $70-130 \%$ for $1 \mathrm{~A}$ in steps of $5 \%$.

\section{So, the Thermal Overload relay is kept at $80 \%$ setting.}

\section{For Short Circuit Protection}

Starting current is 6 times the rated current

Rated current $=145.79 \mathrm{~A}$

Starting current $=6 \times 145.79=874.79 \mathrm{~A}$

Here the starting current is $75 \%$ of the rated voltage.

$\underline{874.79}=1130.38 \mathrm{~A}$

0.75

5.691A passes through the CT secondary

$100 \%$ of $5.651 \mathrm{~A}=565.1 \%$

The instanteous overcurrent relay has the range of 400$2000 \%$ for $1 \mathrm{~A}$ in steps of $50 \%$

So, the Instanteous Overcurrent relay is kept at $600 \%$ setting.

\section{For Negative Phase Sequence Protection}

Here the relay is set at half of the starting current

Starting current $=874.79 \mathrm{~A}$

$\underline{874.79}=437.37 \mathrm{~A}$

2

$\mathrm{Z}_{2} / \mathrm{Z}_{1}=20 \% / 80 \%=25 \%$

The Negative Phase Sequence current relay has the range of $10-40 \%$ for $1 \mathrm{~A}$ in 7 equal steps.
So, the Negative Phase Sequence current relay is kept at $25 \%$ setting.

\section{For under Voiltage Protection}

Primary Voltage $=6.6 \mathrm{kV}$

For under voltage protection the voltage is $70 \%$ of primary voltage

$70 \%$ of $6.6 \mathrm{kV}=4620 \mathrm{~V}$

$\mathrm{PT}$ ratio $=6600 / 110 \mathrm{~V}$

77 V Passes through the PT secondary

The under voltage relay has the range of $70-110 \%$ of rated voltage.

So, for the Under Voltage relay $70 \%$ of $110 \mathrm{~V}$ is selected for setting.

\section{For stalling protection}

The fault current is $1 / 3$ starting current

Starting current $=847.79 \mathrm{~A}$

$$
\frac{874.79}{3}=291.59 \mathrm{~A}
$$

1.457 A passes through the CT secondary $100 \%$ of $1.457 \mathrm{~A}=145.7 \%$

The stalling relay has the range of $150-600 \%$ in steps of $30 \%$

So, the Stalling relay is kept at $\mathbf{1 5 0 \%}$ setting.

\section{SETTING FOR NUMERICAL RELAY}

Table 1: Settings for numerical relay

\begin{tabular}{|l|l|l|l|}
\hline Parameters & Range & Steps & Settings \\
\hline $\begin{array}{l}\text { Thermal } \\
\text { Overload } \\
\text { Protection }\end{array}$ & $5 \%-250 \%$ & $1 \%$ & $77 \%$ \\
\hline $\begin{array}{l}\text { Instantaneous } \\
\text { Overcurrent } \\
\text { Protection }\end{array}$ & $50 \%-1500 \%$ & $50 \%$ & $600 \%$ \\
\hline $\begin{array}{l}\text { Negative } \\
\text { Phase } \\
\text { sequence } \\
\text { Protection }\end{array}$ & $0.2-10 \mathrm{sec}$ & $0.1 \mathrm{sec}$ & $0.2 \mathrm{sec}$ \\
\hline $\begin{array}{l}\text { Stalling } \\
\text { Protection }\end{array}$ & $1500 \%$ & $50 \%$ & $200 \%$ \\
\hline
\end{tabular}




\section{PSCAD AND SIMULATIONS}

\subsection{Simulation and Results}

\subsubsection{Model for Effect of Torque on Speed}

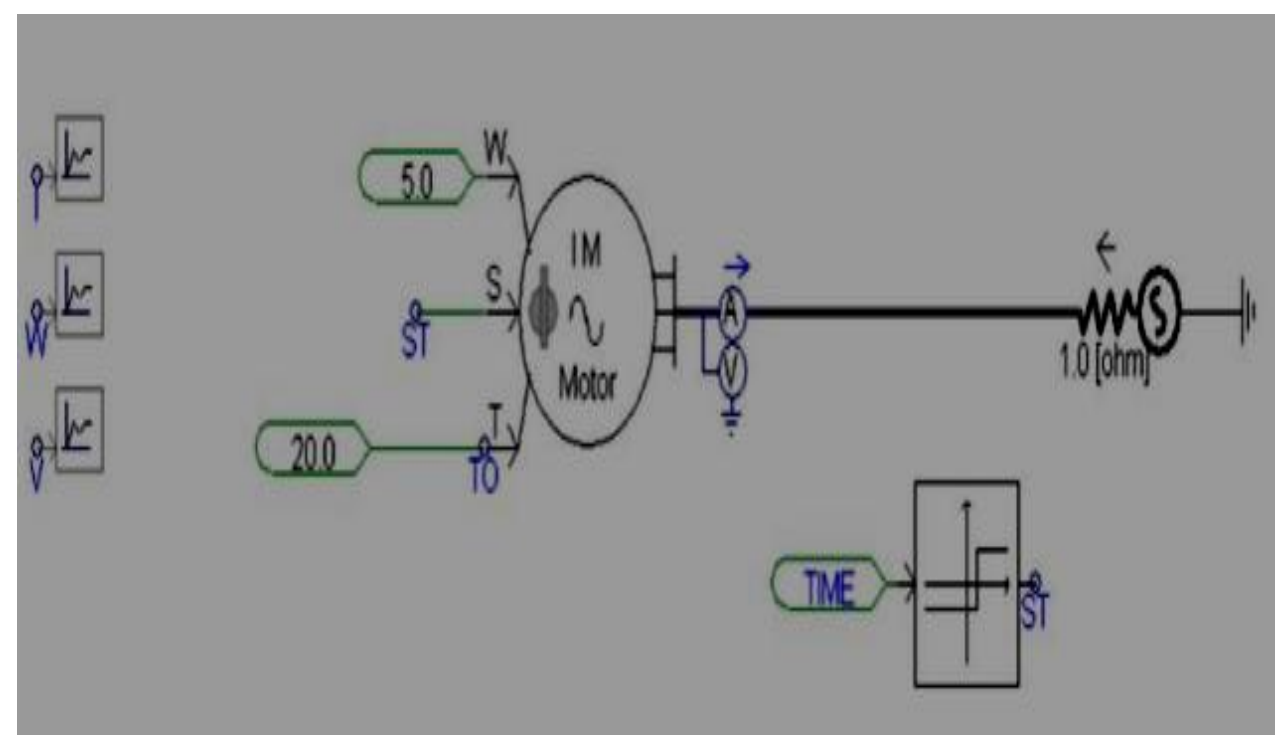

Fig -6: Simulation model for effect of torque on speed

From the above figure, an induction motor is given a supply of $11 \mathrm{kV}$ at $50 \mathrm{~Hz}$. An ammeter and voltmeter is kept in series with motor to measure the current and voltage of motor respectively. The motor is started in the speed mode and then it is switched to torque mode after 0.1 seconds. From the figure shown below it can seen that as the motor switches to torque mode, the speed gradually decreases.

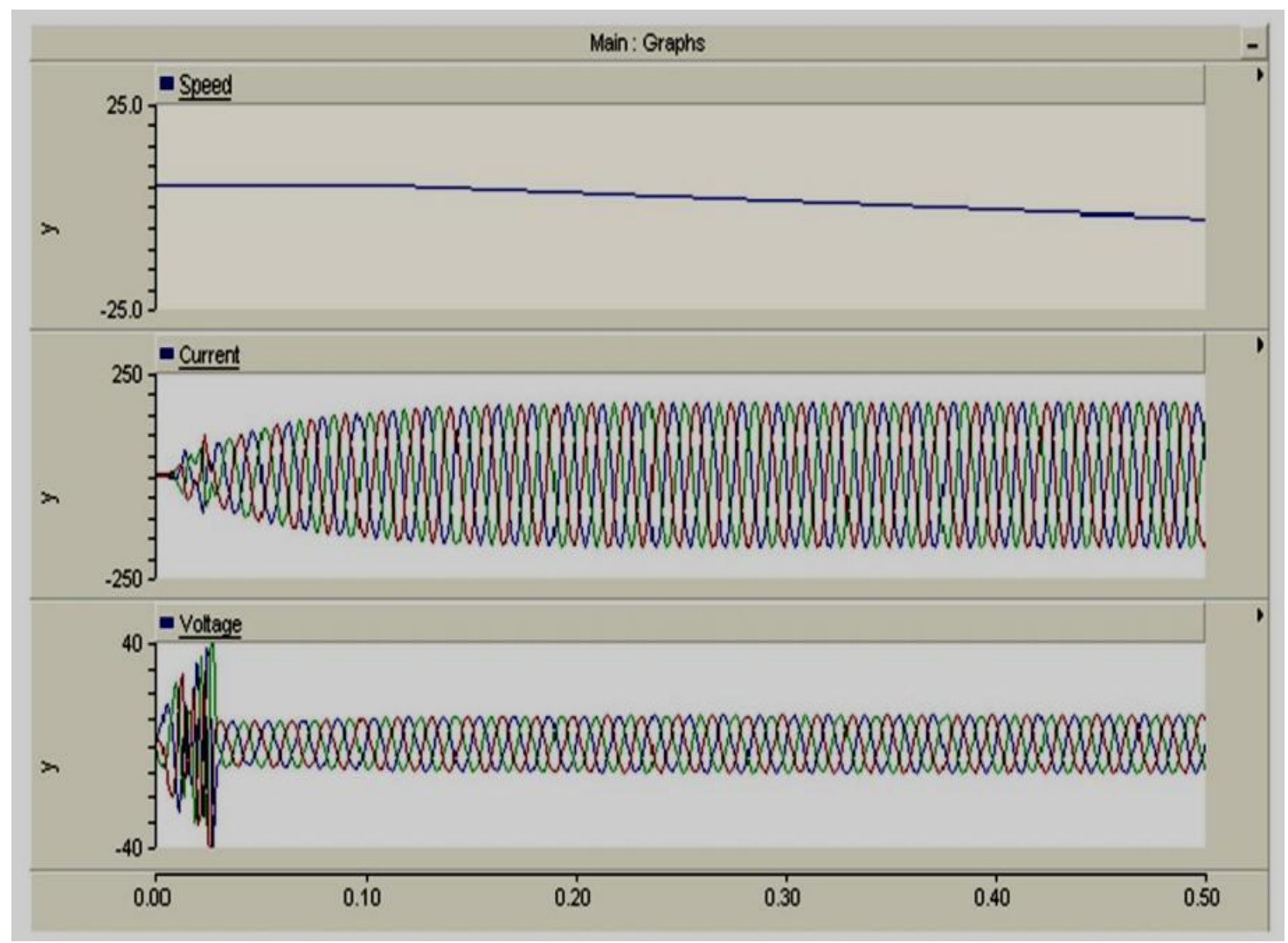

Fig -7: Output waveform 


\subsubsection{Model for Overcurrent Protection}

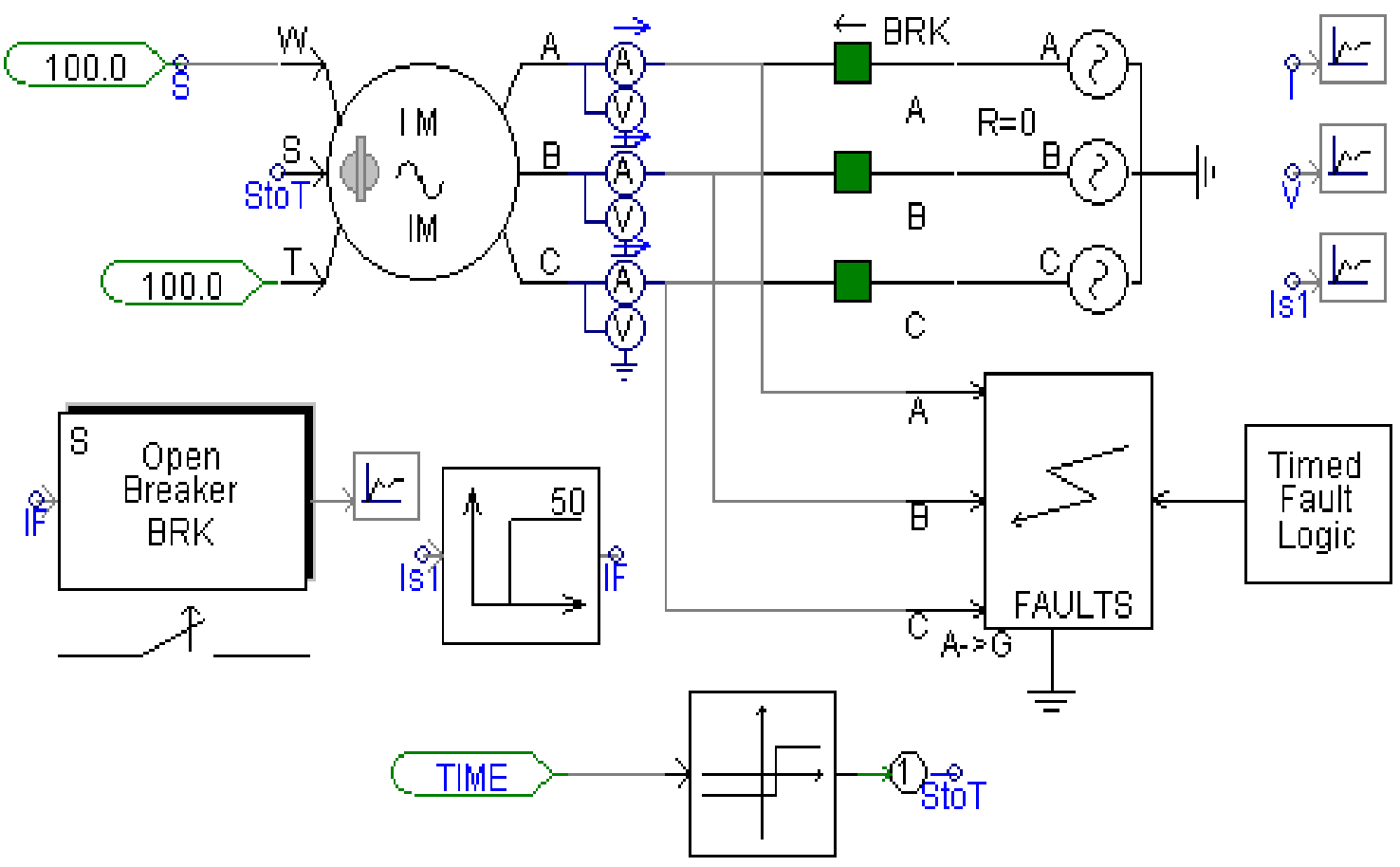

Fig -8: Simulation for overcurrent protection

In this simulation the switching from speed mode to torque mode is done at 0.2 seconds. The ratings of the motor are kept same with a 3-phase supply of $415 \mathrm{~V}$ at $50 \mathrm{~Hz}$. The fault block is used to apply a line to ground fault on line A after 0.3 seconds.

The graph below shows that as soon as the fault is applied, a tripping signal is generated which opens the circuit breakers.

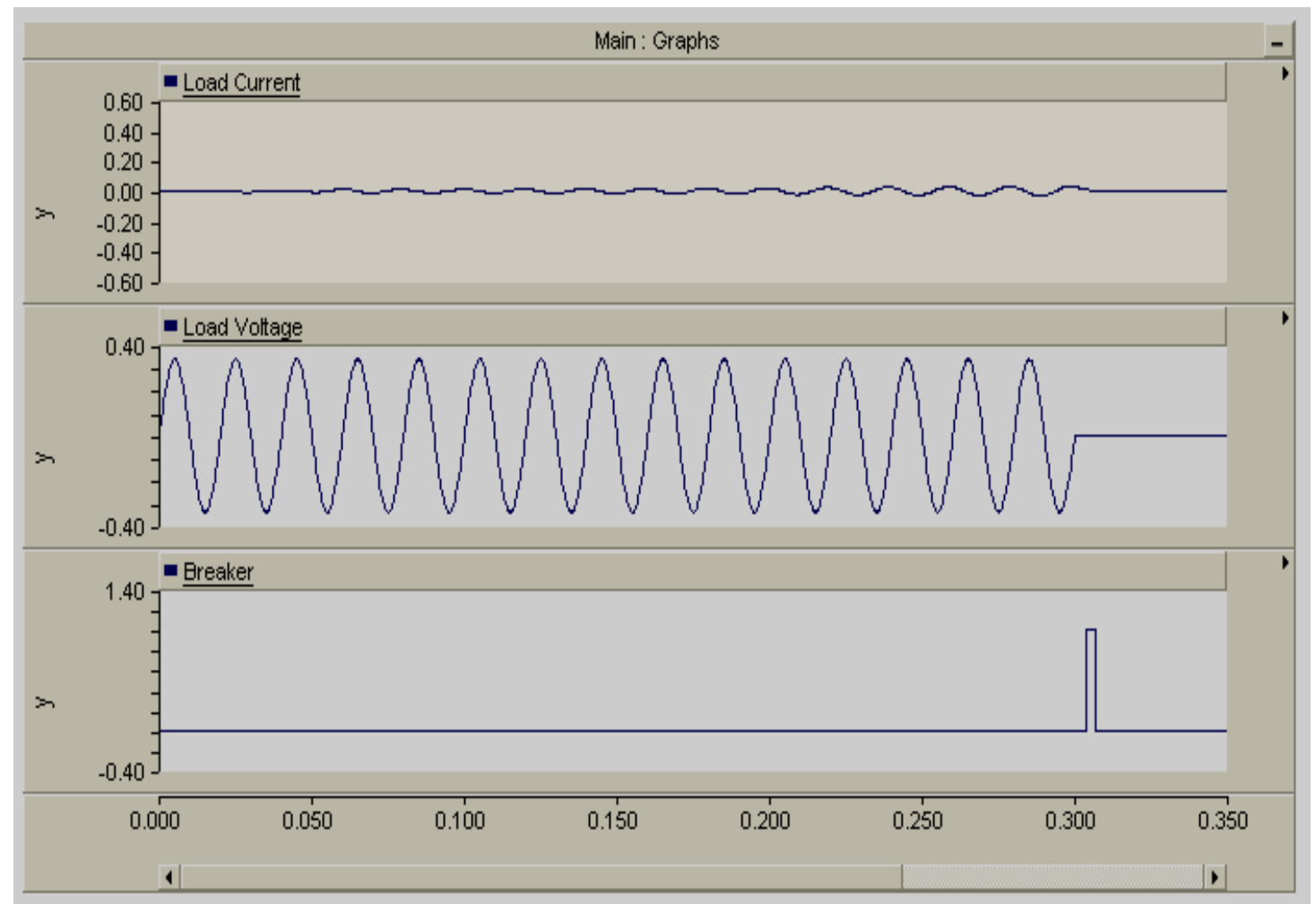

Fig -9: Output waveform before and after tripping

Figure 9 shows that when the source current raises to its peak value due to fault in line, the trip signal is generated by the relay and the breaker opens isolating the motor from the faulty section and source current becomes zero. 


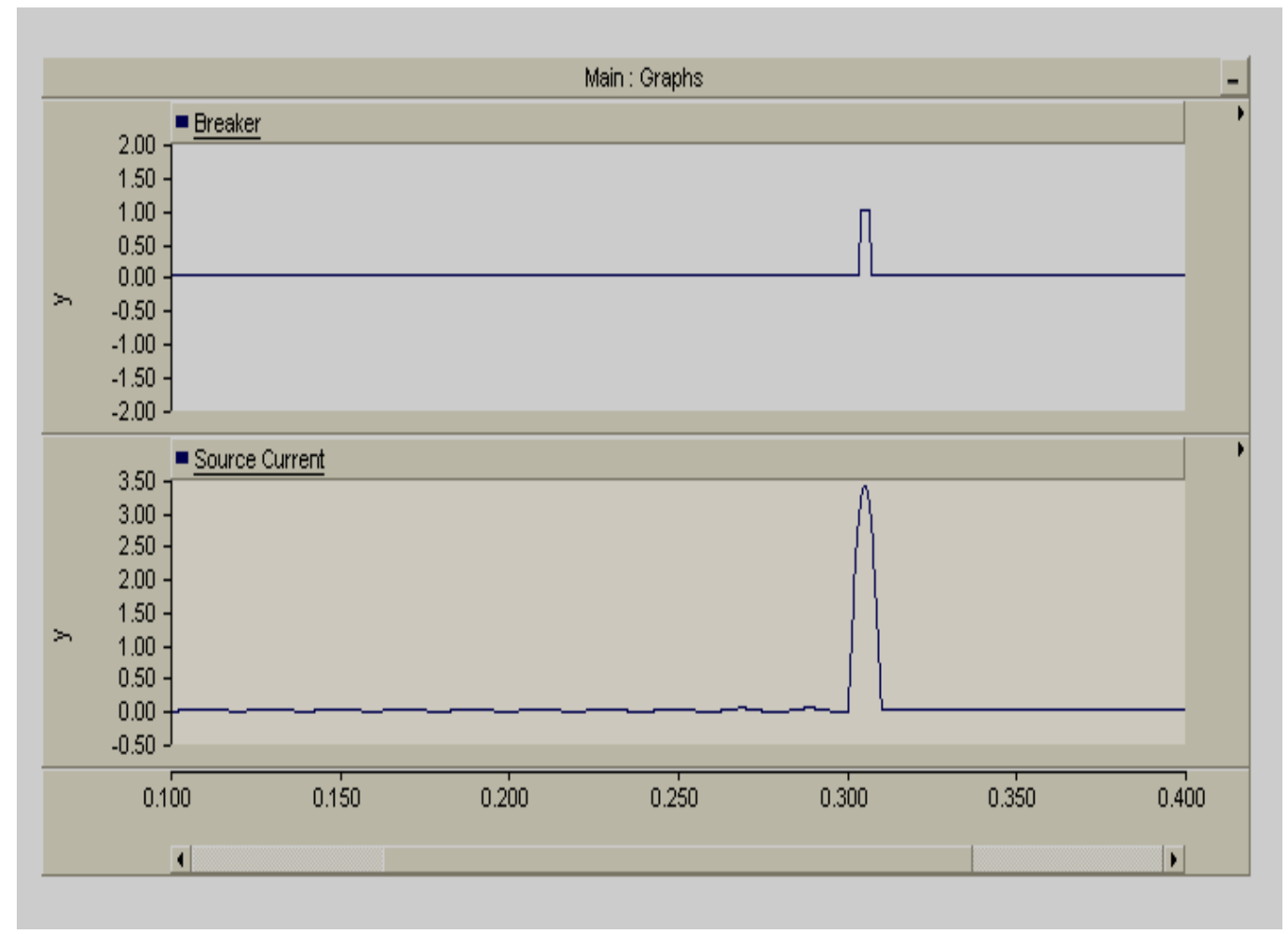

Fig -10: Behavior of source current

\section{CONCLUSION}

By setting relays as per this paper, many motors which are used for different purposes in industries can be protected from various abnormalities and faults. The proper setting of the relay is done which is attached with the motor so that they operate as per their characteristic and the system can be saved, thus proper task is completed without any interruption. By doing this, eventually maintenance of the power station or industry can be decreased.

\section{ACKNOWLEDGEMENTS}

We would like to acknowledge all the faculties of Electrical Department of CGPIT, Uka Tarsadia University, Bardoli those who always extended their hands in all kind of problems regarding this project. We would also like to thank our family and friends who supported us to led this paper towards success.

\section{REFERENCES}

[1]. “A Novel Protecting Method for Induction Motor against Faults Due to Voltage unbalance and Single Phasing" - Mrs. M. SUIDHA, Dr. P. ANBALAGAN.

[2]. "Stall protection of large Induction motors" - Jose DeCastro, Roy Beck, Charles Cai, Luke Yu.

[3]. "Behaviour of Induction Motor due to Voltage Sag and Short Interruptions." - Juan C. Gomez, Medhat M. Morcos, Claudio A. Reineri Gabriel N. Campetelli.

[4]. "Thermal overload protection of Induction motors under waveform distortion"- MojtabaKhederzadeh.

[5]. "Simulating Voltage Sag Using PSCAD Software "Kang Chia Yang, Hushairi HJ Zen, Nurlkhmar, Najemeenb Binti Ayob.
[6]. "Power System Protection and Switch Gear" Bhuvanesh A Oza Nirmal-Kumar C Nair, Rashesh P Mehta, Vijay H Makwana.

[7]. "Principles of Electrical Machines"- V.K. Mehta.

[8]. "Fundamental of Power System Protection"- Y.G. Paithankar S.R. Bhide.

\section{BIOGRAPHIES}

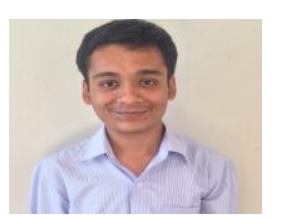

Pathik N. Shah, pursuing B.Tech in Electrical Engineering at CGPIT, Uka Tarsadia University, Bardoli, Surat E-Mail ID: pathikshah05@gmail.com

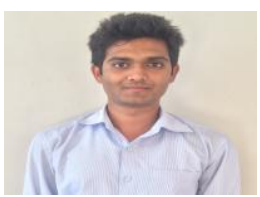

Smith N. Patel , pursuing B.Tech in Electrical Engineering at CGPIT, Uka Tarsadia University ,Bardoli, Surat Email ID: smithpatel55@gmail.com

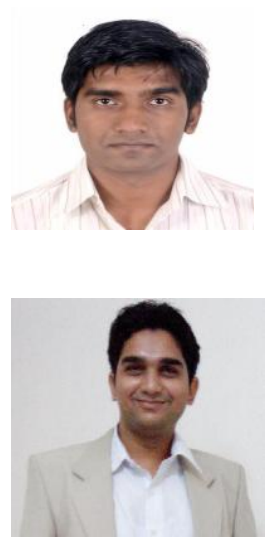

Jay A. Patel, Assistant Professor in Department of Electrical Engineering at CGPIT,

Uka Tarsadia University, Bardoli, Surat E-Mail ID: jay.patel@utu.ac.in

Umang S. Wani, Assistant Professor in Department of Electrical Engineering at CGPIT, Uka Tarsadia University, Bardoli, Surat

E-Mail ID: umang.wani@utu.ac.in 